\title{
Atmosphere-dependent stability and mobility of catalytic Pt single atoms and clusters on $\gamma-\mathrm{Al}_{2} \mathrm{O}_{3}$
}

Caroline Dessal, ${ }^{\mathrm{a}}$ Alexis Sangnier,${ }^{\mathrm{b}, \mathrm{c}}$ Céline Chizallet, ${ }^{\mathrm{b}}$ Christophe Dujardin, ${ }^{\mathrm{d}}$ Franck Morfin, ${ }^{\mathrm{a}}$

Jean-Luc Rousset, ${ }^{\mathrm{a}}$ Mimoun Aouine, ${ }^{\mathrm{a}}$ Matthieu Bugnet, ${ }^{\mathrm{e}}$ Pavel Afanasiev, ${ }^{\mathrm{a}}$ Laurent Piccolo ${ }^{\mathrm{a} *}$

a. Univ Lyon, Université Claude Bernard - Lyon 1, CNRS, IRCELYON - UMR 5256, 2 Avenue Albert Einstein, F-69626 VILLEURBANNE CEDEX, France. *E-mail:

Laurent.Piccolo@ircelyon.univ-lyon1.fr

b. IFP Energies nouvelles, Rond-point de l'échangeur de Solaize, 69360 Solaize, France. *E-mail: Celine.Chizallet@ifpen.fr

c. IFP Energies nouvelles, 1 et 4 avenue de Bois-Préau, 92852 Rueil-Malmaison, France.

d. Univ. Lille, ENSCL, UMR 8181, Unité de Catalyse et Chimie du Solide, Cité Scientifique Bât. C3, 59655 Villeneuve d'Ascq Cedex, France.

e. Univ Lyon, INSA Lyon, UCBL Lyon 1, MATEIS, UMR 5510 CNRS, 7 Avenue Jean Capelle, F69621 Villeurbanne Cedex, France.

\section{Electronic Supplementary Information}

- Figures S1-S15

○ S1-S2: XAS

○ S3-S12: STEM

○ S13-S15: DFT

- Table S1

- Theoretical Methods S1 


\section{Supplementary figures S1-S15}
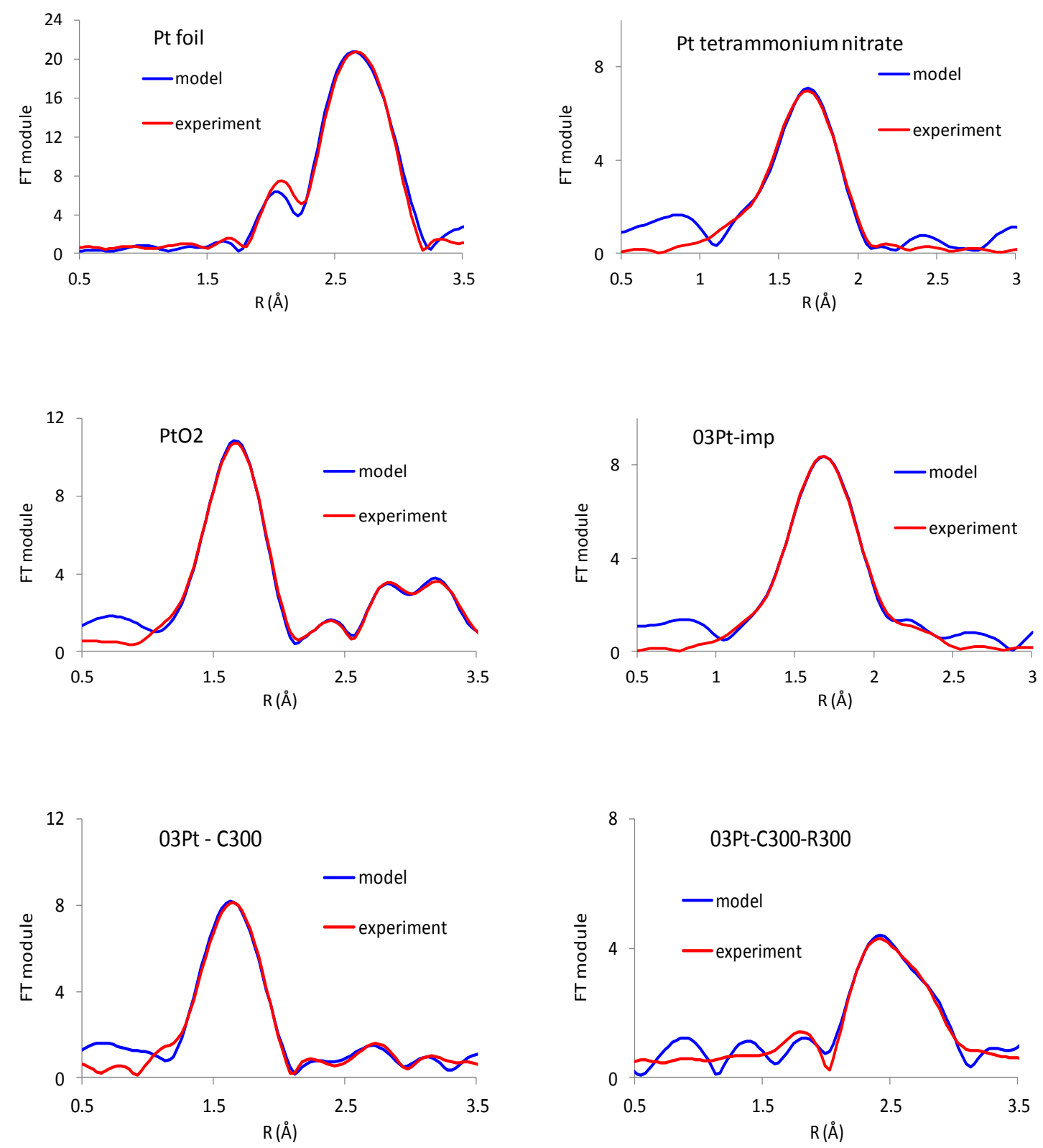

Fig. S1. EXAFS data analysis (I). R-space EXAFS fit graphs for the supported Pt samples and references. 

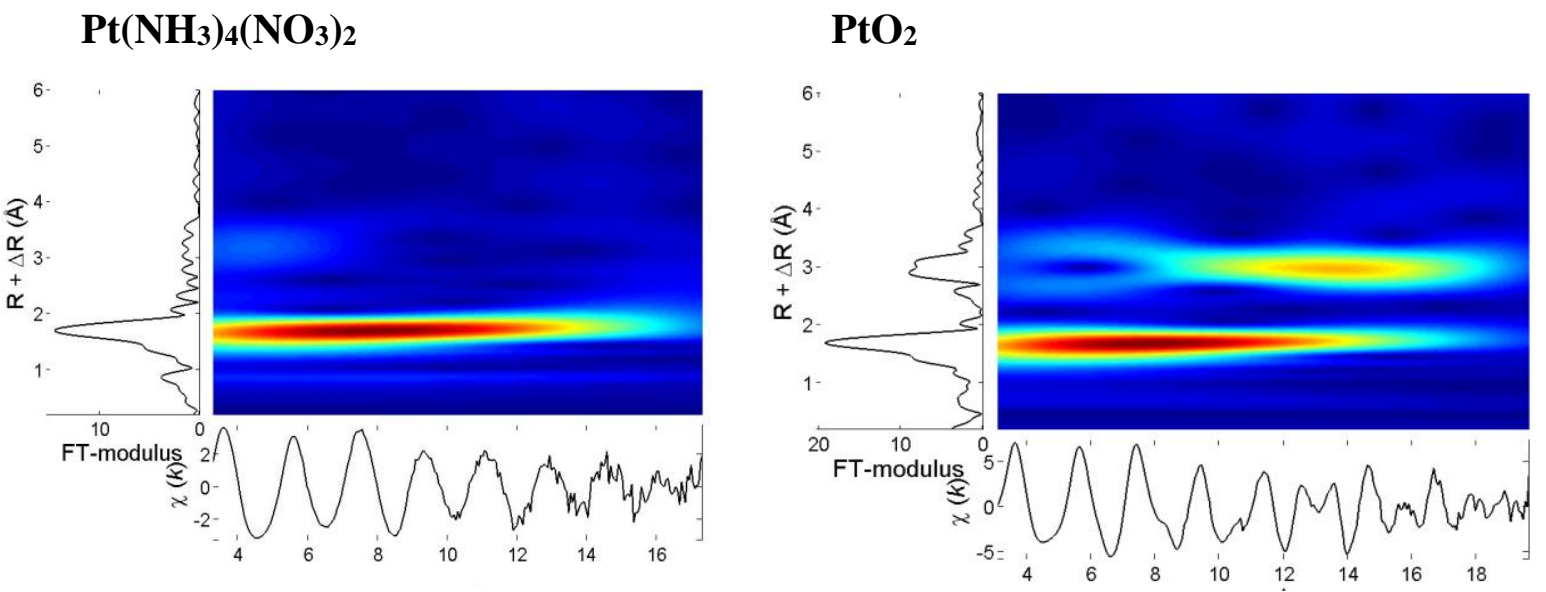

\section{Pt foil}

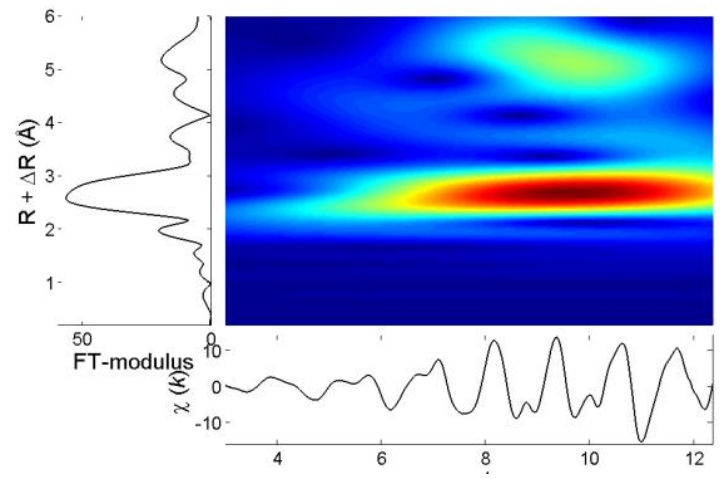

\subsection{Pt-imp}

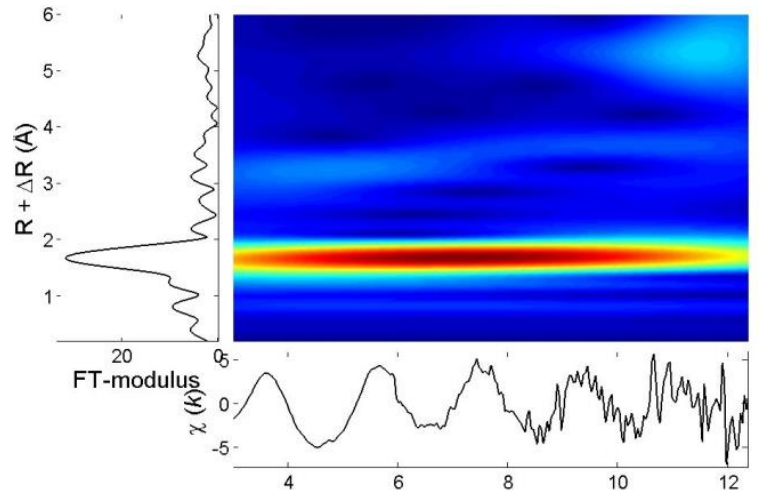

0.3Pt-C300

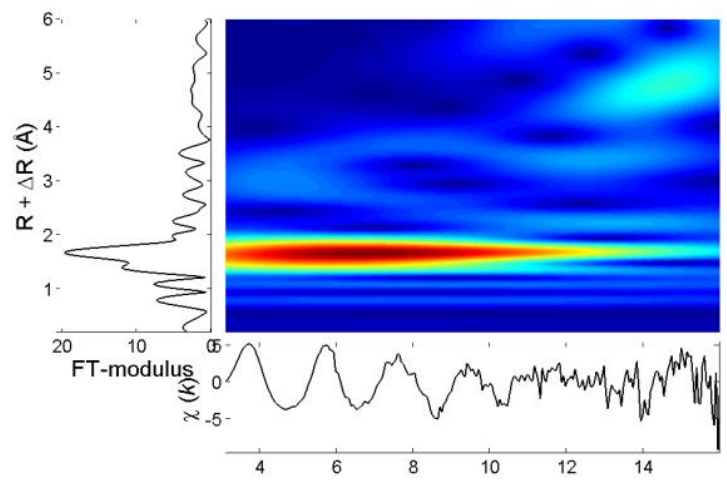

\subsection{Pt-C300R300}

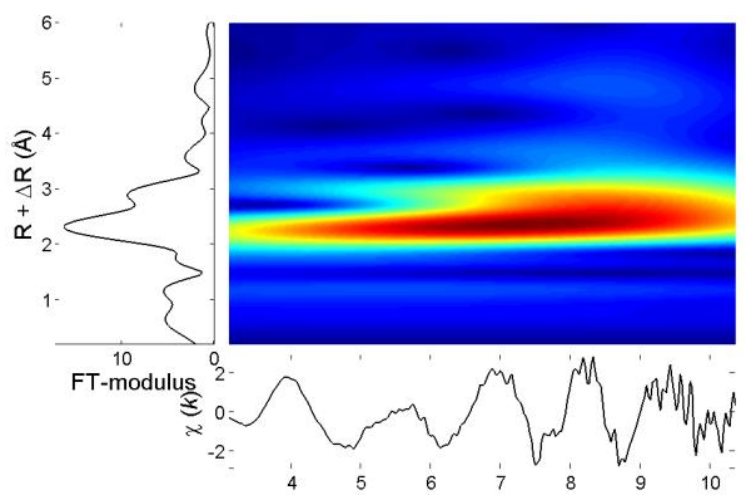

Fig. S2. EXAFS data analysis (II). Cauchy wavelet transforms of the EXAFS spectra for several samples. 

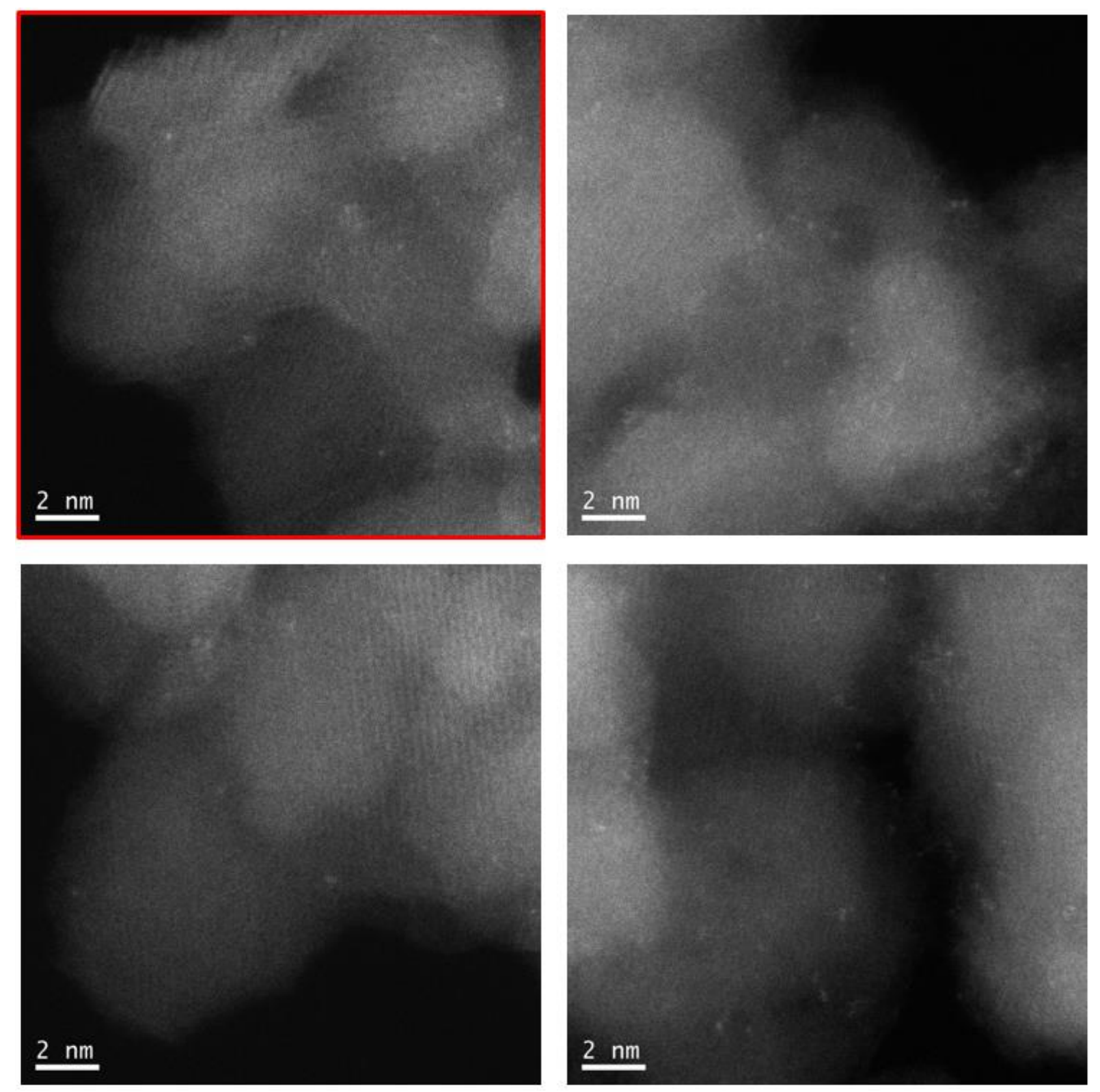

Fig. S3. STEM imaging of the $0.3 \mathrm{wt} \% \mathrm{Pt} / \boldsymbol{\gamma}-\mathrm{Al}_{2} \mathrm{O}_{3} \mathrm{SAC}$. STEM-ADF images of the 0.3Pt-C300 sample. The image with red border is that of the main article. Only single Pt atoms are observed. 

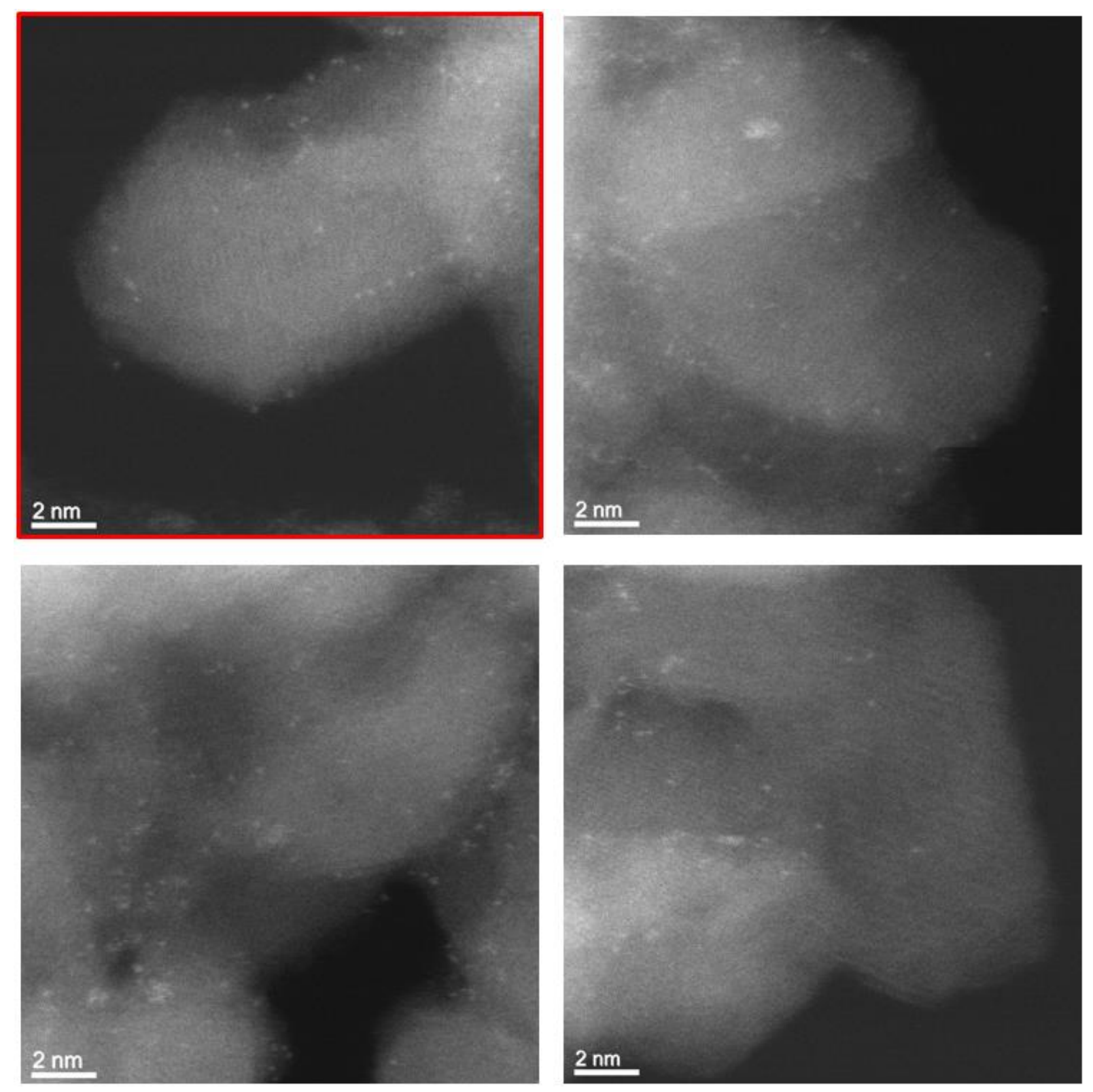

Fig. S4. STEM imaging of the $0.5 \mathrm{wt} \% \mathrm{Pt} / \boldsymbol{\gamma}-\mathrm{Al}_{2} \mathrm{O}_{3} \mathrm{SAC}$. STEM-ADF images of $0.5 \mathrm{Pt}-\mathrm{C} 300$ sample. Mostly single atoms are observed, together with some small clusters. 


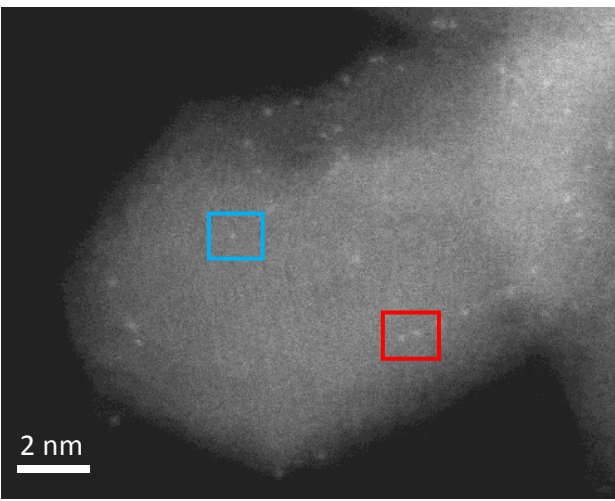

No filter
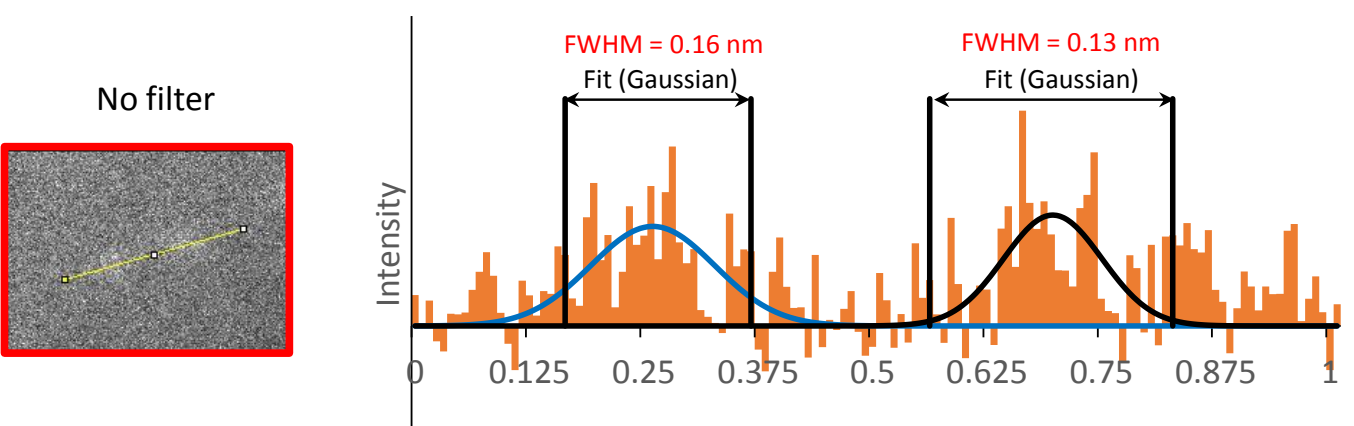

Distance (nm)
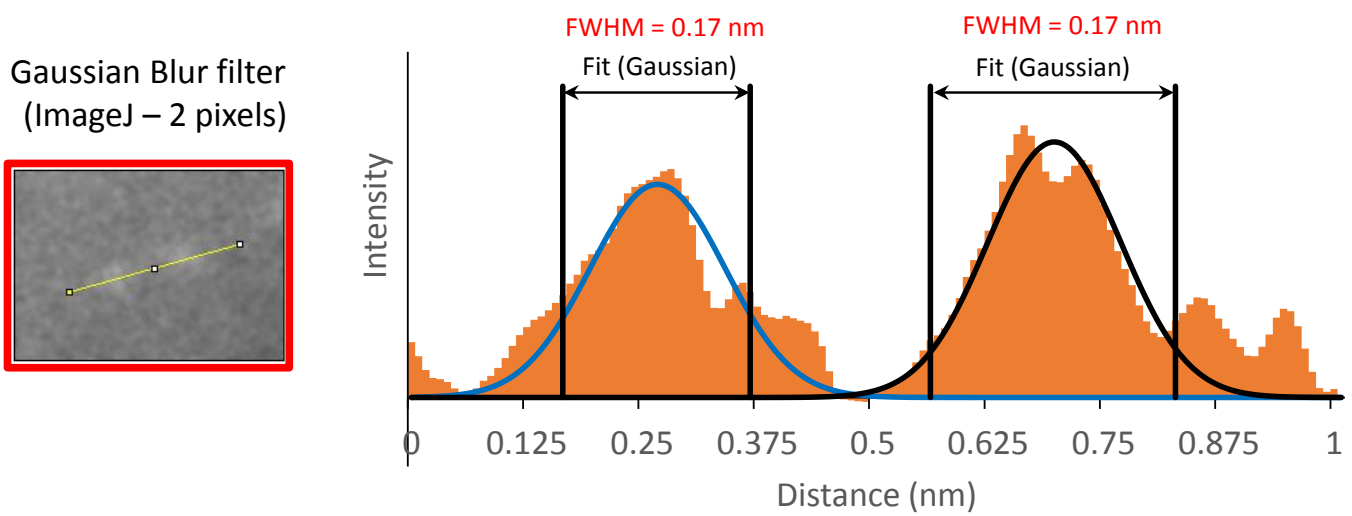

Gaussian Blur filter (ImageJ - 2 pixels)

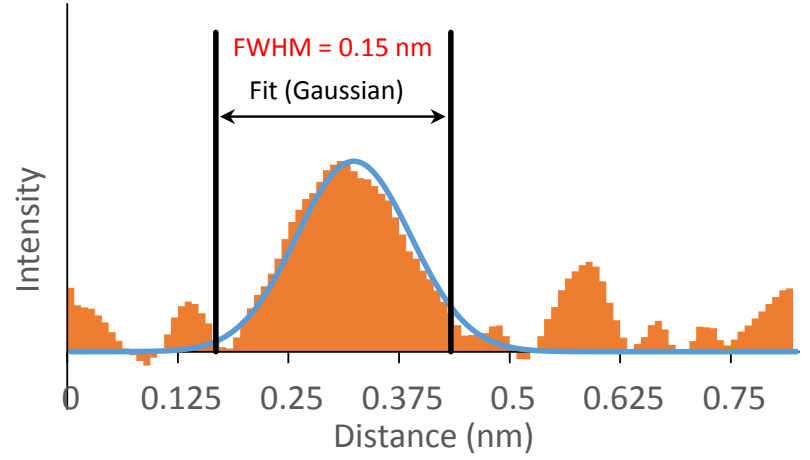

Fig. S5. STEM analysis of single atoms. Linescans from the STEM-ADF image of Fig. 2b, with or without Gaussian filtering. The FWHM corresponding to the size of a single atom is $0.15 \pm 0.02$ nm. 


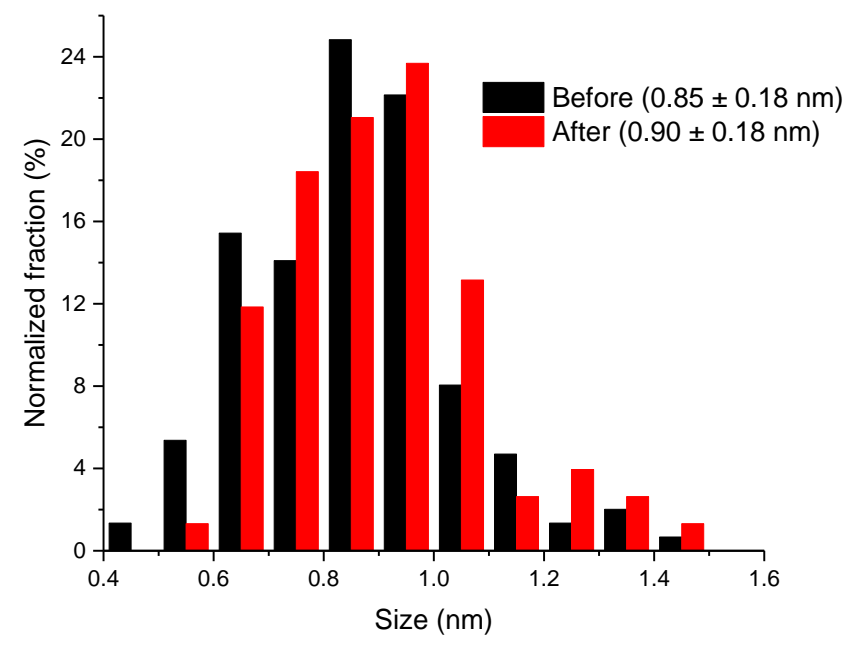

b

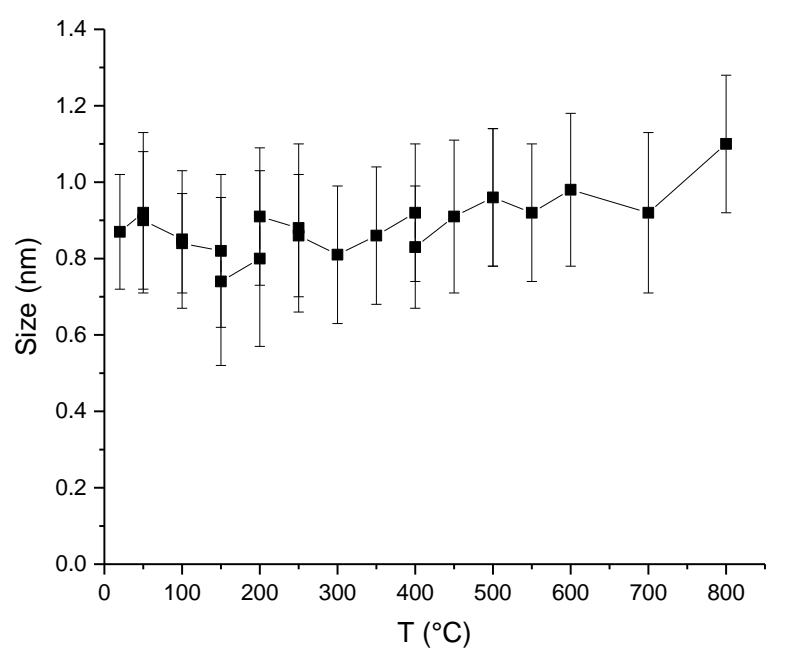

Fig. S6. Particle size analysis of the $0.5 \mathrm{wt} \% \mathrm{Pt} / \gamma-\mathrm{Al}_{2} \mathrm{O}_{3}$ sample used for E-STEM experiment in $\mathbf{H}_{2}$. a, Size histograms determined from the STEM images acquired at room temperature, before and after the E-STEM experiment performed on the 0.5Pt-C300 sample under $500 \mathrm{~Pa} \mathrm{H}_{2}$ at increasing temperatures up to $800^{\circ} \mathrm{C}$. $\mathbf{b}$, Evolution of the mean size of the Pt clusters throughout the E-STEM experiment. The size is defined as the diameter of the circle having the same surface area as the projected image. 

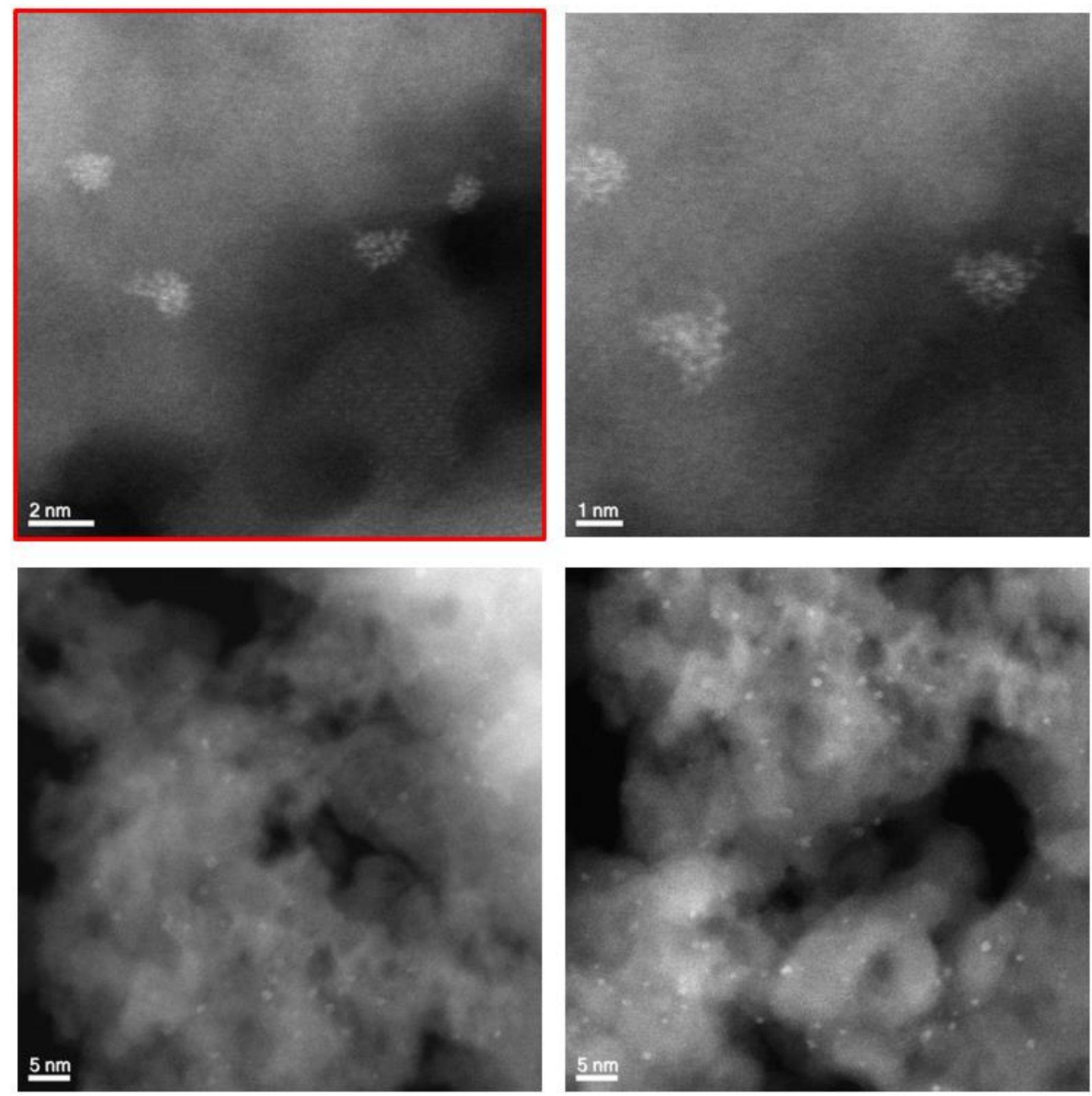

Fig. S7. Imaging of $0.5 \mathrm{wt} \% \mathrm{Pt} / \gamma-\mathrm{Al}_{2} \mathrm{O}_{3}$ after E-STEM experiment in $\mathrm{H}_{2}$. The latter was performed at $\mathrm{H}_{2}$ pressure up to $500 \mathrm{~Pa}$ and temperature up to $800{ }^{\circ} \mathrm{C}(0.5 \mathrm{Pt}-\mathrm{C} 300 \mathrm{R} 800)$. Only clusters are observed (size $0.9 \pm 0.2 \mathrm{~nm}$ ) in the STEM-ADF images. The clusters look relatively flat, with a loose density of $\mathrm{Pt}$ atoms. 

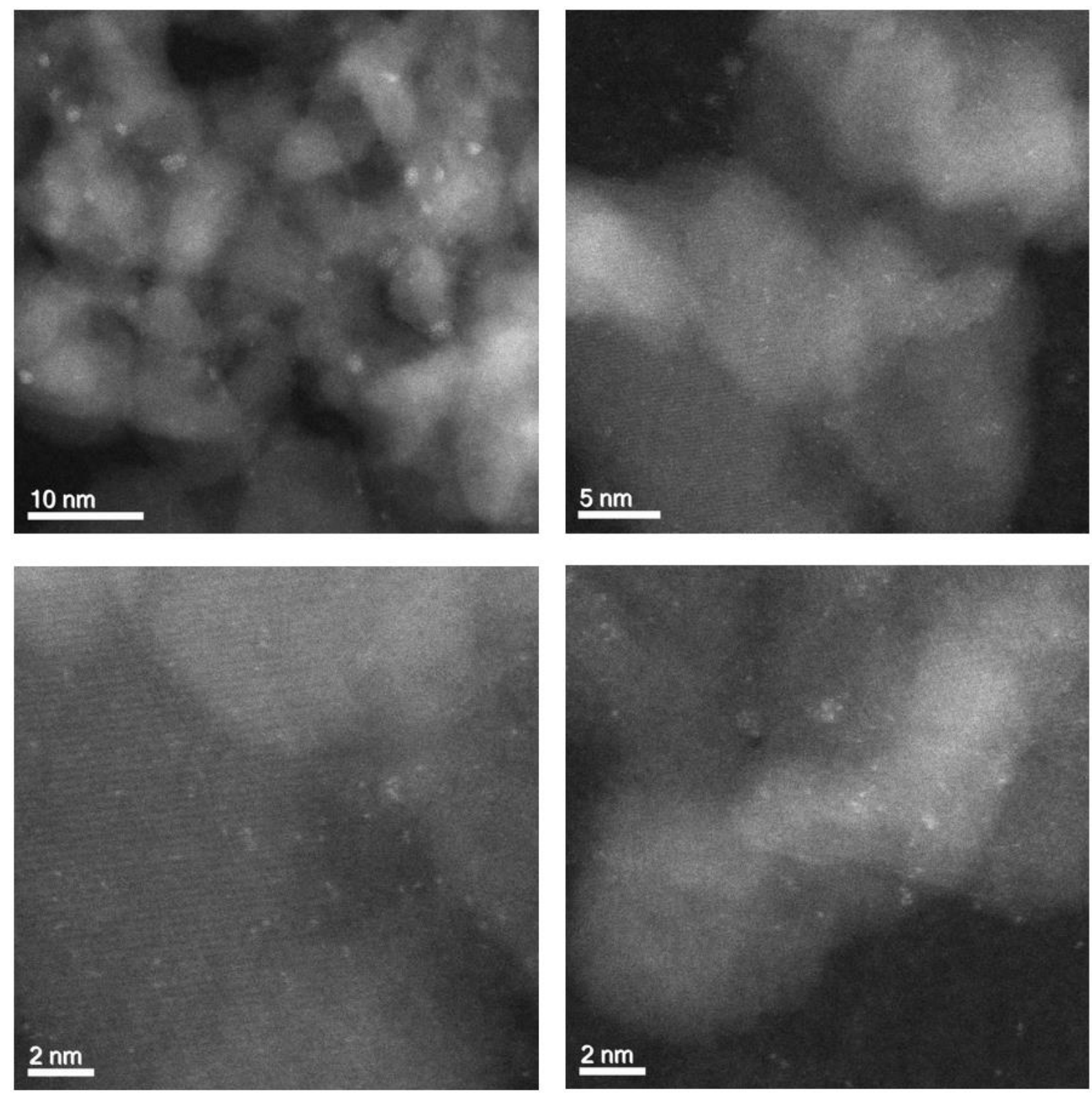

Fig. S8. STEM imaging of $0.5 \mathrm{wt} \% \mathrm{Pt} / \gamma-\mathrm{Al}_{2} \mathrm{O}_{3}$ after hydrogen exposure at room temperature. STEM-ADF images of the 0.5Pt-C300 sample after exposure to $10^{5} \mathrm{~Pa} \mathrm{H}_{2}$ at RT in XAS experiment. Single atoms and clusters are present. 

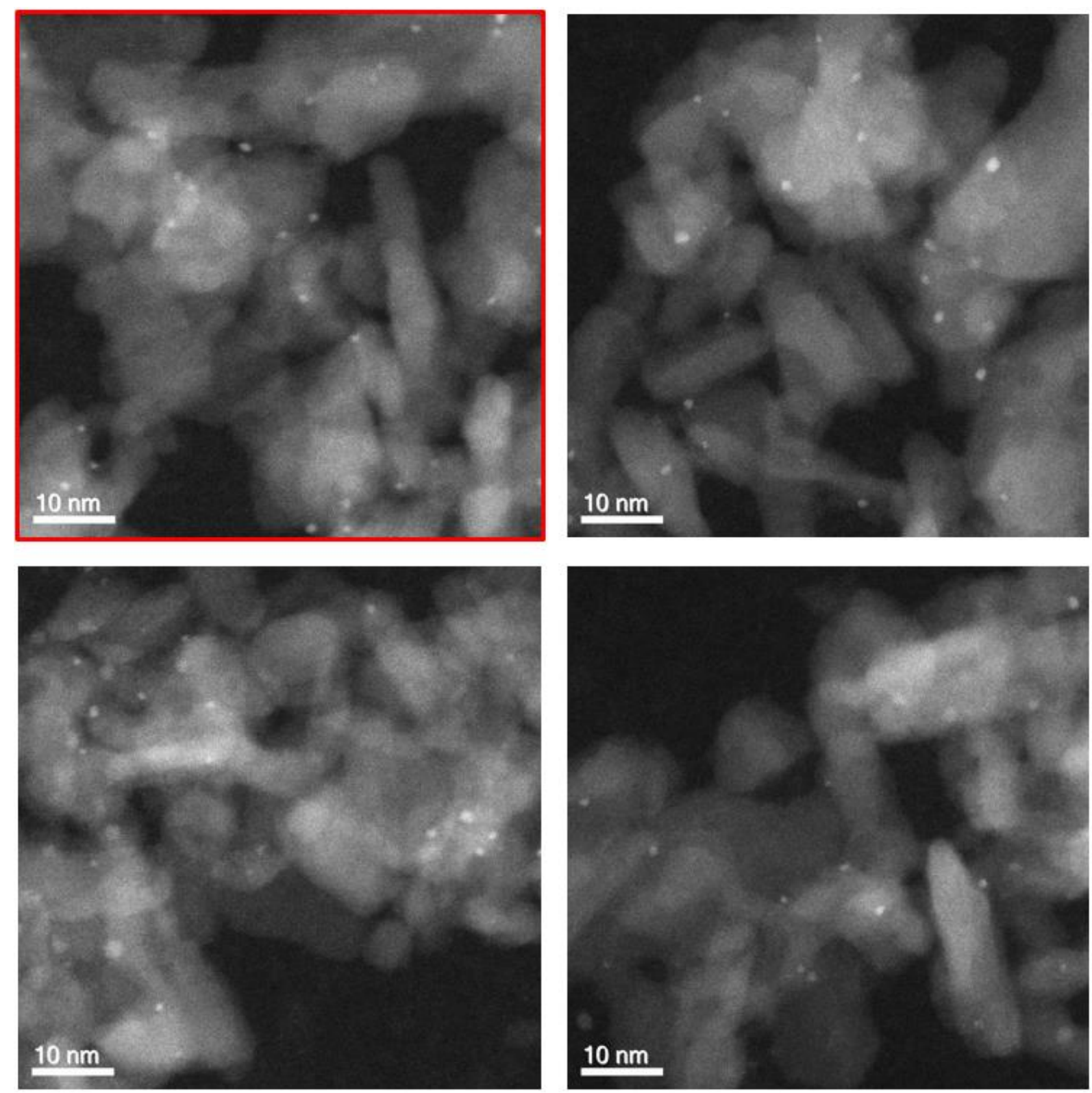

Fig. S9. STEM imaging of $0.3 \mathrm{wt} \% \mathrm{Pt} / \boldsymbol{\gamma}-\mathrm{Al}_{2} \mathrm{O}_{3}$ after hydrogen exposure at high temperature. STEM-ADF images of the 0.3Pt-C300R300 sample obtained after XAS experiment consisting of air calcination at $300{ }^{\circ} \mathrm{C}$ of alumina impregnated with $\mathrm{Pt}\left(\mathrm{NH}_{3}\right)_{4}\left(\mathrm{NO}_{3}\right)_{2}$ (initial XAS sample) followed by $\mathrm{H}_{2}$ reduction at up to $300{ }^{\circ} \mathrm{C}$. The image with red border is that of the main article. Mostly clusters $(0.96 \pm 0.25 \mathrm{~nm})$ are observed. 

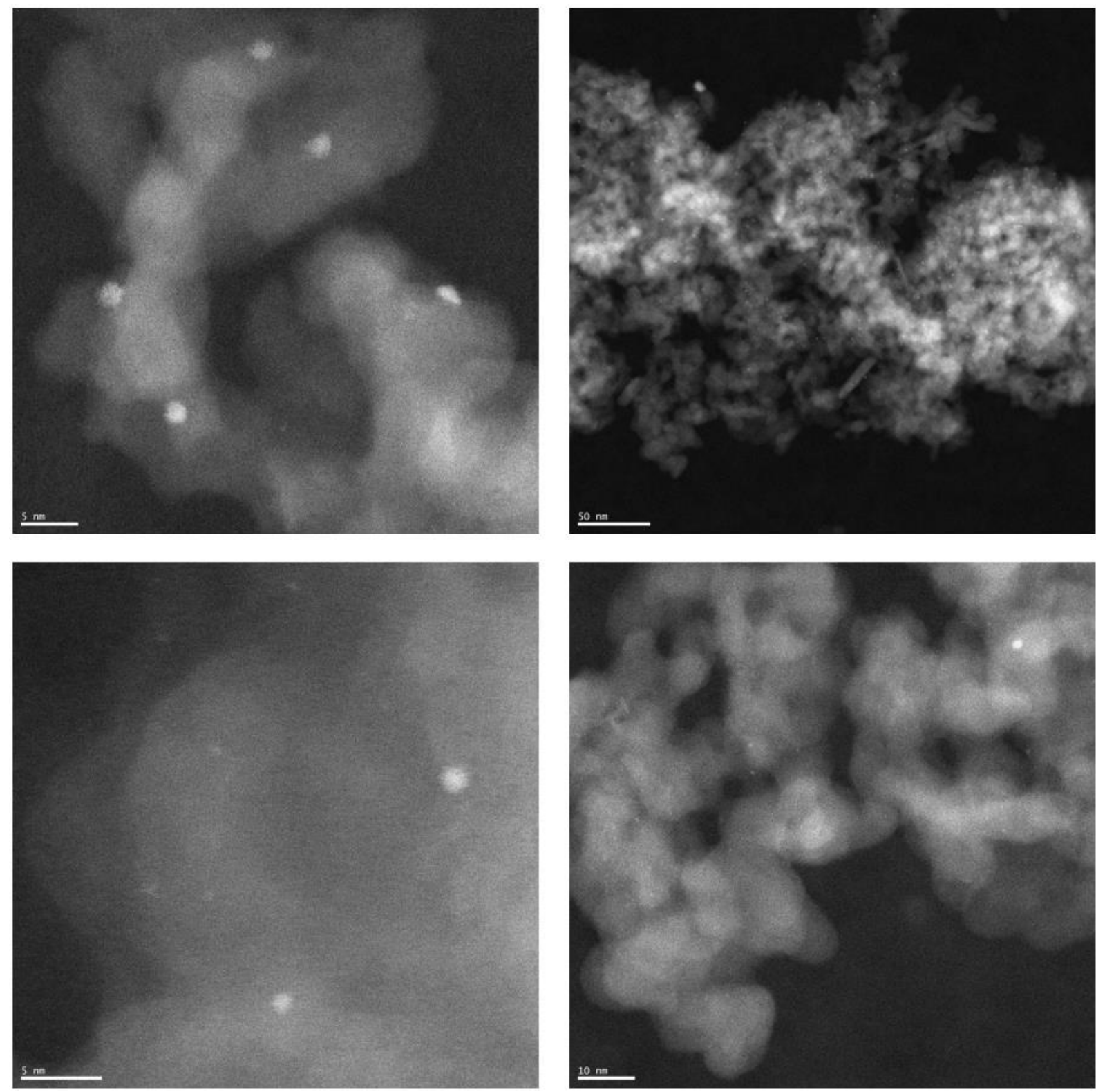

Fig. S10. Imaging of $0.5 \mathrm{wt} \% \mathrm{Pt} / \gamma-\mathrm{Al}_{2} \mathrm{O}_{3}$ in $\mathrm{O}_{2}$ before E-STEM experiment. STEM-ADF images of the catalyst at RT under $130 \mathrm{~Pa} \mathrm{O}_{2}$, after exposure of the $0.5 \mathrm{Pt}-\mathrm{C} 300$ sample to $40 \mathrm{~Pa}$ $\mathrm{H}_{2}$ and just before the E-STEM experiment at variable temperature under $\mathrm{O}_{2}$. Single atoms, oligomers (few-atom clusters) and bigger clusters are present. The average Pt particle size is $0.7 \pm$ $0.4 \mathrm{~nm}$. The pressure was chosen low to maintain high resolution. 

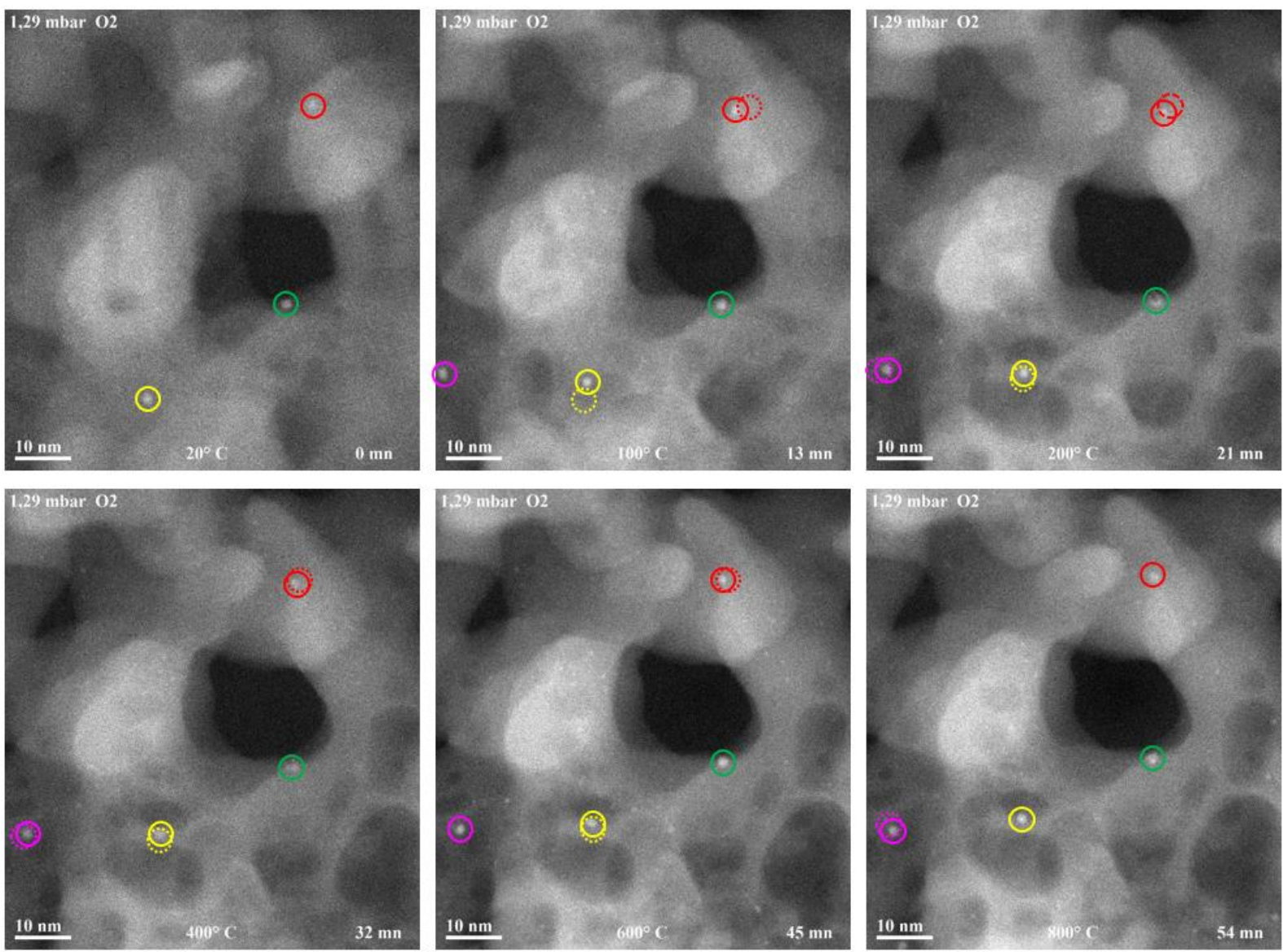

Fig. S11. Microscopic visualization of Pt cluster stability in oxidizing conditions. STEM-ADF images recorded at increasing times $(0,13,21,32,45$ and $54 \mathrm{~min})$ and temperatures $(20,100,200$, 400, 600 and $800{ }^{\circ} \mathrm{C}$ ) for $0.5 \mathrm{wt} \% \mathrm{Pt} / \gamma-\mathrm{Al}_{2} \mathrm{O}_{3}$ (0.5Pt-C300 sample) under $130 \mathrm{~Pa} \mathrm{O}_{2}$. Colored circles show individual clusters. From a frame to the next, an identical location is displayed as a dotted circle with the same color. The full movie (S2) can be found in SI. It further shows that the clusters disappear between 800 and $1000{ }^{\circ} \mathrm{C}$, temperature at which the support looks severely affected. 


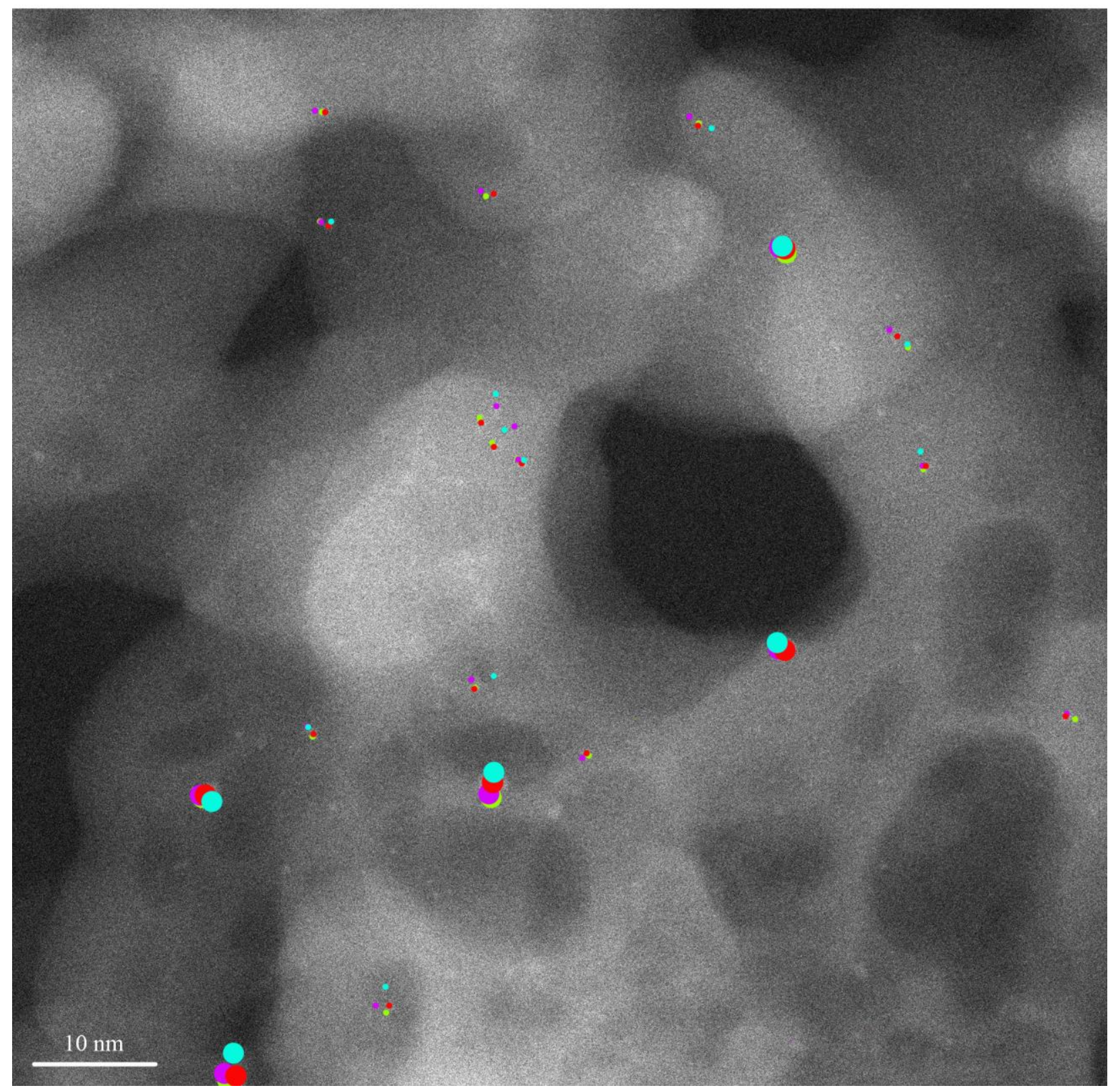

Fig. S12. Microscopic visualization of $\mathrm{Pt}$ single atom and oligomer stability in oxidizing conditions. Superposition of particle locations throughout the previous E-STEM experiment on $0.5 \mathrm{wt} \% \mathrm{Pt} / \gamma-\mathrm{Al}_{2} \mathrm{O}_{3}$ (0.5Pt-C300 sample) under $130 \mathrm{~Pa} \mathrm{O}$. Disks and dots correspond to big clusters and oligomers/single atoms, respectively. Green, magenta, red and cyan colors correspond to $400,500,600$ and $800{ }^{\circ} \mathrm{C}$, respectively. The background STEM-ADF image was recorded at $600{ }^{\circ} \mathrm{C}$. 
a

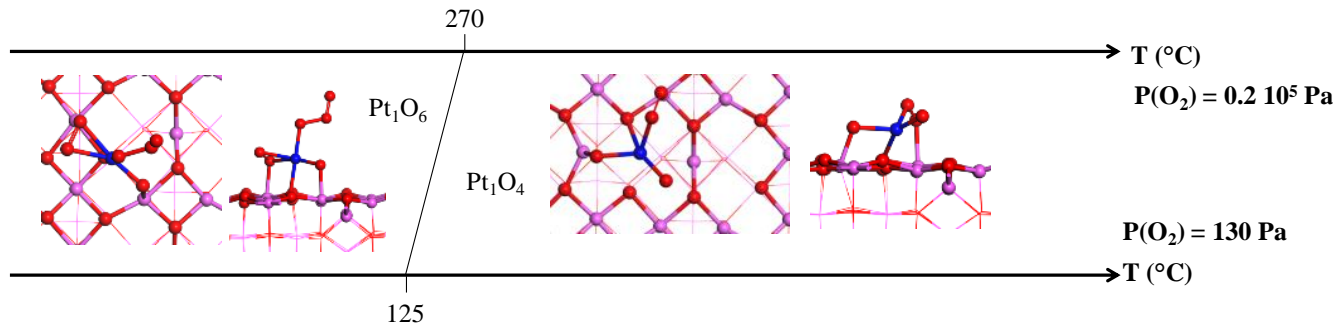

b

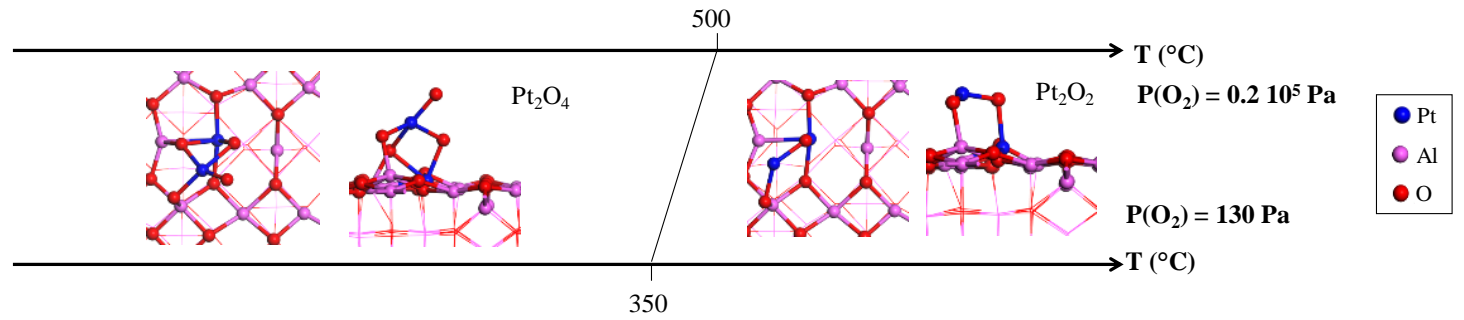

c

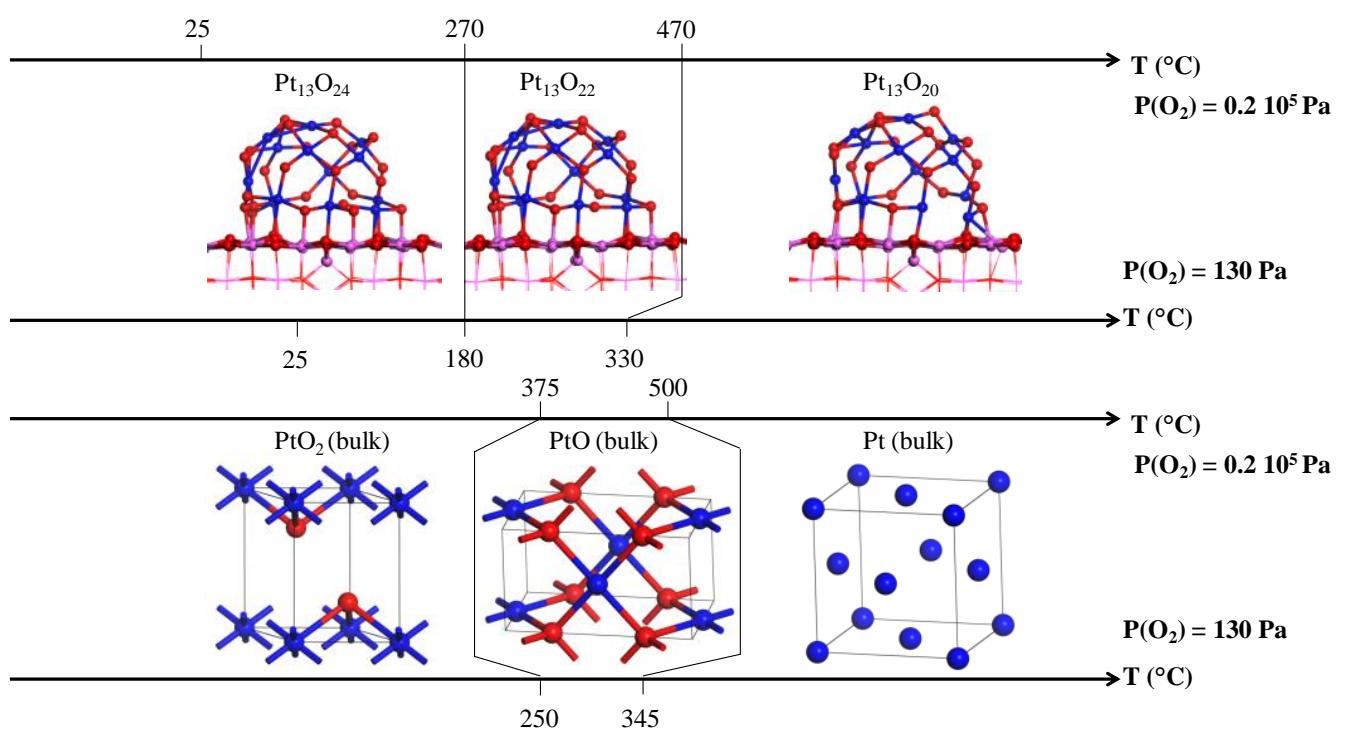

Fig. S13. Influence of $\mathrm{O}_{2}$ pressure and temperature on $\mathrm{Pt}$ structure and adhesion. Structures of the most stable oxidized $\mathrm{Pt}_{x} / \gamma-\mathrm{Al}_{2} \mathrm{O}_{3}(100)$ clusters in XAS (upper axis) and E-STEM (lower axis) conditions, with $x=1(\mathbf{a}), 2$ (b) and $13(\mathbf{c})$, and for bulk platinum and oxides (d), as a function of the temperature and the pressure of $\mathrm{O}_{2}$, as predicted by DFT calculations. 
a

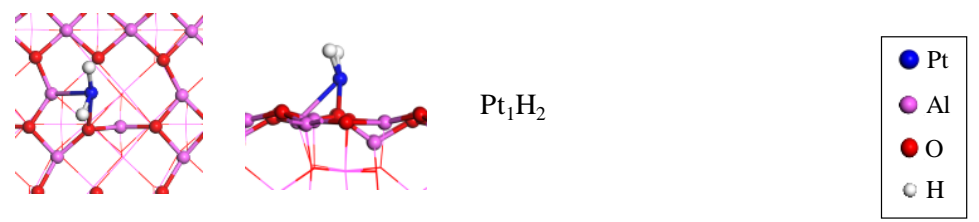

b
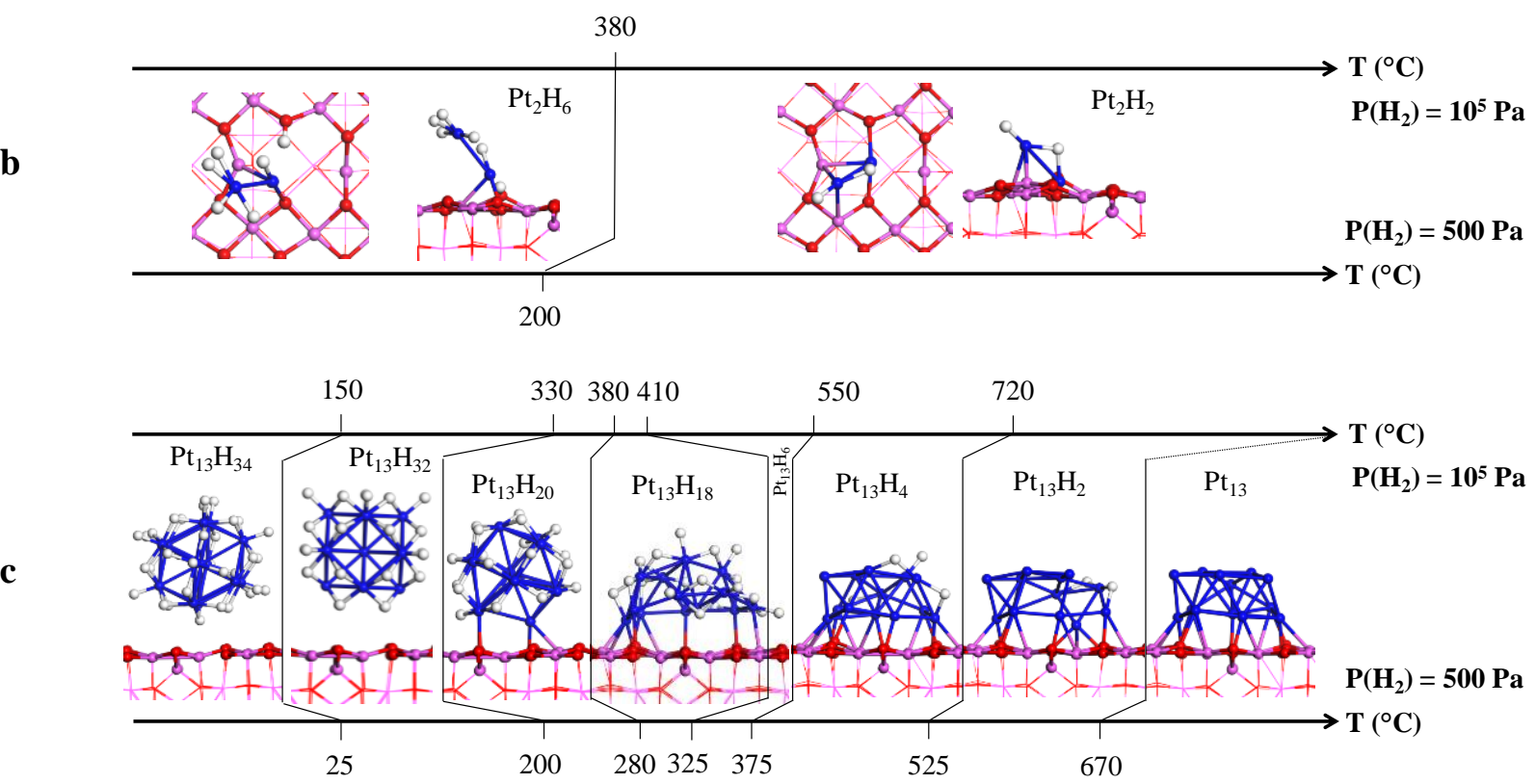

Fig. S14. Influence of $\mathrm{H}_{2}$ pressure and temperature on $\mathrm{Pt}$ structure and adhesion. Structures of the most stable reduced $\mathrm{Pt}_{x} / \gamma-\mathrm{Al}_{2} \mathrm{O}_{3}(100)$ clusters in XAS (upper axis) and E-STEM (lower axis) conditions, with $x=1,2$ and 13, as a function of the temperature and the $\mathrm{H}_{2}$ pressure, as predicted by DFT calculations. a, $x=1: \mathrm{Pt}_{1} \mathrm{H}_{2}$ is always the most stable system. $\mathbf{b}, x=2$, with two possible coverage of $\mathrm{H}$. c, $x=13$ : hydride phase for $\mathrm{T}<280{ }^{\circ} \mathrm{C} / 380{ }^{\circ} \mathrm{C}$ with absence of metal-support bonds for $\mathrm{T}<200{ }^{\circ} \mathrm{C} / 330{ }^{\circ} \mathrm{C}$, metallic phase in strong interaction with the support for $\mathrm{T}>$ $280^{\circ} \mathrm{C} / 380{ }^{\circ} \mathrm{C}$. 


\section{Number of ads orbed $\mathrm{H} / \mathrm{O}$ atoms per cluster}

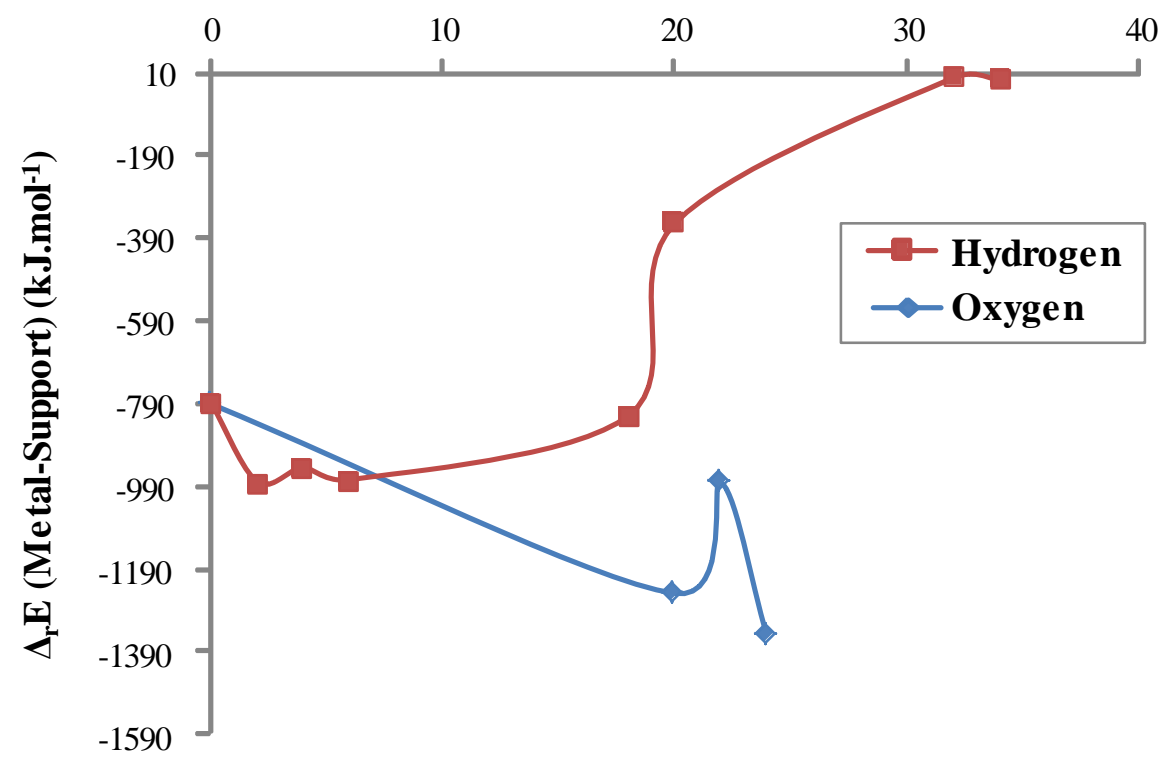

Fig. S15. Influence of $\mathbf{H}$ or $\mathbf{O}$ adsorption on metal-support interaction. The metal-support interaction energy $\left(\Delta_{r} E\right)$, calculated at $0 \mathrm{~K}$ as a function of the number of $\mathrm{H}$ or $\mathrm{O}$ atoms adsorbed on $\gamma-\mathrm{Al}_{2} \mathrm{O}_{3}(100)$-supported $\mathrm{Pt}_{13}$ clusters, is defined as: $\Delta_{r} E$ (Metal-Support) $=E$ (total) $-E$ (support) - E(cluster), E(total) being the energy of the total system (cluster, support and adsorbates), $E$ (support) the energy of the support alone at the geometry of the total system, and $E$ (cluster) the energy of the cluster with its adsorbates at the geometry of the total system. The lower the interaction energy, the stronger the interaction. 


\section{Supplementary table S1. EXAFS fitting results.}

\begin{tabular}{|c|c|c|c|c|}
\hline Scatterer atom & $C N$ & $r(\AA)$ & $\sigma^{2}\left(\AA^{2}\right)$ & $\Delta E_{0}(e V)^{b}$ \\
\hline \multicolumn{5}{|c|}{$\mathrm{Pt}\left(\mathrm{NH}_{3}\right)_{4}\left(\mathrm{NO}_{3}\right)_{2}: R=0.027$} \\
\hline $\mathrm{N}$ & $4^{\mathrm{a}}$ & $2.03(2)$ & $0.0028(4)$ & $8.0(5)$ \\
\hline \multicolumn{5}{|c|}{$\mathrm{PtO}_{2}: R=0.029$} \\
\hline $\mathrm{O}$ & $6^{\mathrm{a}}$ & $2.04(2)$ & $0.0051(4)$ & $9.2(9)$ \\
\hline $\mathrm{Pt}$ & $3.5(9)$ & $3.17(5)$ & $0.0038(4)$ & $9.2(9)$ \\
\hline \multicolumn{5}{|c|}{ 0.3Pt-imp: $R=0.047$} \\
\hline $\mathrm{O}$ & $5.2(6)$ & $2.04(3)$ & $0.005(1)$ & $9(2)$ \\
\hline \multicolumn{5}{|c|}{ 0.3Pt-C300: $R=0.06$} \\
\hline $\mathrm{O}$ & $5.5(8)$ & $2.03(3)$ & $0.0055(7)$ & $9(2)$ \\
\hline \multicolumn{5}{|c|}{ 0.3Pt-C300R300: $R=0.07$} \\
\hline $\mathrm{O}$ & $1.4(7)$ & $1.99(7)$ & $0.007(4)$ & $8(2)$ \\
\hline $\mathrm{Pt}$ & $4.2(8)$ & $2.71(6)$ & $0.008(4)$ & $8(2)$ \\
\hline \multicolumn{5}{|c|}{ Pt foil: $R=0.015$ (first shell only) } \\
\hline $\mathrm{Pt}$ & $11.6(5)$ & $2.77(2)$ & $0.0035(8)$ & $9(1)$ \\
\hline
\end{tabular}

a Integer number constrained. ${ }^{\mathrm{b}}$ Constrained to be equal for same fit. The amplitude reduction factor $S_{0}{ }^{2}=$ 0.9 for all samples; $C N$ is the coordination number; $r$ is the distance between absorbing and backscattering atoms; $\sigma^{2}$ is the Debye-Waller factor; $\Delta E_{0}$ is the energy variance. 


\section{Supplementary Theoretical Methods S1.}

The comparison, in terms of thermodynamic stability, with bulk structures was done in $\mathrm{O}_{2}$ and $\mathrm{H}_{2}$ atmospheres:

- In $\mathrm{O}_{2}$ atmosphere, $\mathrm{PtO}$ and $\mathrm{PtO}_{2}$ are to be considered. Experimental data exist regarding the respective thermal stabilities of these solids for a given $\mathrm{O}_{2}$ pressure. From data gathered in the Outokumpu HSC Chemistry suite (distributed by Outokumpu Research Oy), the phase diagram represented in Fig. S13d was obtained. In air at $300^{\circ} \mathrm{C}$, the most stable bulk system is expected to be $\mathrm{PtO}_{2}$. In these conditions, the sintering free energy from supported $\mathrm{Pt}_{13} \mathrm{O}_{22}$ was estimated according to the following reaction equation:

$$
\frac{1}{13}\left\{P t_{13} O_{22} / A l_{2} O_{3}\right\}+\frac{2}{13} O_{2(g)}=P t O_{2(b u l k)}+\frac{1}{13}\left\{A l_{2} O_{3}\right\}
$$

By this approach, we assume that the metal oxide / support interaction is negligible for very big particles, when normalized by the number of platinum atoms.

- $\quad$ In $\mathrm{H}_{2}$ atmosphere, hydrides have to be considered. However, bulk platinum hydride does not exist. An equivalent thermodynamic diagram can thus not be constructed. However, a sintering free energy can be estimated, considering the following reaction equation:

$$
\frac{1}{13}\left\{P t_{13} H_{32} / A l_{2} O_{3}\right\}=P t_{(b u l k)}+\frac{1}{13}\left\{A l_{2} O_{3}\right\}+\frac{32}{2 \times 13} H_{2(g)}
$$

The ability of the (100) alumina surface to stabilize $\mathrm{Pt}_{13}$ clusters was compared with that of the hydrated (110) alumina surface in ref. ${ }^{[4]}$. Similar trends were found, with loss of the metal-support interaction upon increase in hydrogen coverage. The stabilization of Pt atoms and clusters in the absence of adsorbates was also shown to obey similar rules between the dehydrated (100) surface and the hydrated (110) one. ${ }^{[2]}$ Thus, the trends found in the present work are most likely general, for several kinds of surface structures.

\section{References}

[1] A. Gorczyca, V. Moizan, C. Chizallet, O. Proux, W. Del Net, E. Lahera, J.-L. Hazemann, P. Raybaud, Y. Joly, Angew. Chem. Int. Ed. 2014, 53, 12426-12429.

[2] C. Mager-Maury, C. Chizallet, P. Sautet, P. Raybaud, ACS Catal. 2012, 2, 1346-1357. 